\title{
$\mathbf{2 H}$-Azirines as dipolarophiles
}

\author{
Teresa M. V. D. Pinho e Melo,* Ana L. Cardoso, Clara S. B. Gomes and \\ António M. d'A. Rocha Gonsalves \\ Departamento de Química, Faculdade de Ciências e Tecnologia, Universidade de Coimbra, 3004-535 Coimbra, Portugal \\ Received 20 May 2003; accepted 13 June 2003
}

\begin{abstract}
H-Azirine-3-carboxylates unsubstituted at C-2 act as dipolarophiles in the reaction with diazomethane giving new 4,5-dihydro-3 $H$-pyrazole derivatives. The synthesis of a pyrimidine was also achieved via 1,3-dipolar cycloaddition of methyl 2-bromo-3-phenyl-2 $\mathrm{H}$-azirine-2-carboxylate with an azomethine ylide.
\end{abstract}

(C) 2003 Elsevier Ltd. All rights reserved.

$2 H$-Azirines represent a particular type of imine-based dipolarophiles. The strain inherent in the $2 H$-azirine ring system allows to overcome the low reactivity normally associated to $N$-alkylimines. ${ }^{1}$ The reaction of diazomethane with 2-aryl-3-methyl-2 $\mathrm{H}$-azirines to give allyl azides was the first example reported of 1,3-dipolar cycloaddition of $2 \mathrm{H}$-azirines acting as a $2 \pi$-component. ${ }^{2}$ Subsequently, it has been demonstrated that $2 \mathrm{H}$-azirines participate also in 1,3-dipolar cycloaddition with nitrile oxides and with azomethine ylides. ${ }^{1}$ In this communication we report our studies aiming at extending the use of $2 \mathrm{H}$-azirines as dipolarophiles.

The synthesis of 2-halo- $2 H$-azirines starting from $\alpha$ oxophosphorus ylides and the study of their reactivity is one of our current interests. ${ }^{3} \mathrm{We}$ became interested in exploiting the use of these 2-halo- $2 \mathrm{H}$-azirines as dipolarophiles.

Methyl 2-bromo-3-phenyl-2 $H$-azirine-2-carboxylate 1 was prepared ${ }^{3 a}$ and attempts were made to carry out its reaction with diazomethane. However, complex mixtures were obtained, indicating that the cycloadduct generated from diazomethane and the 2-halo- $2 \mathrm{H}$-azirines can undergo ring opening by various competitive pathways in agreement with the work described by Storr et al. ${ }^{4}$<smiles>COC(=O)C1(Br)N=C1c1ccccc1</smiles>

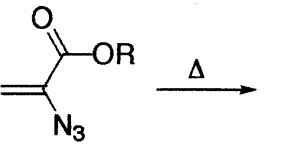

2a, $R=B n$
$\mathbf{2 b}, R=M e$

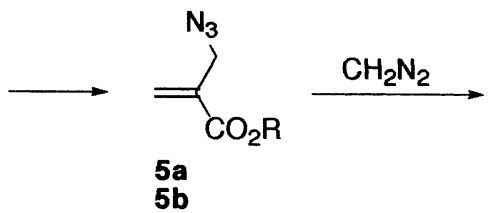

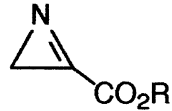

$3 \mathbf{a}$

$\mathbf{3 a}$
$\mathbf{3 b}$

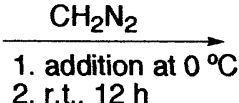

2. r.t., $12 \mathrm{~h}$

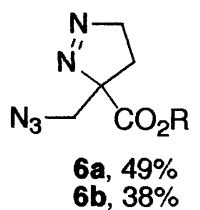

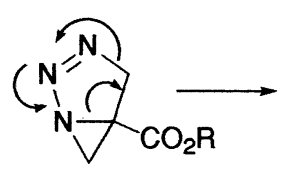

$4 a$

Scheme 1.

Keywords: $2 H$-azirines; 1,3-dipolar cycloaddition; $3 H$-pyrazole; pyrimidine.

* Corresponding author. Fax: +351 239 826068; e-mail: tmelo@ci.uc.pt 
This result led us to study the reaction of diazomethane with a simpler C-2 unsubstituted $2 H$-azirine-3-carboxylate 3a (Scheme 1). This $2 H$-azirine was generated from benzyl $\alpha$-azidoacrylate $\mathbf{2 a}$ by thermolysis, following a known synthetic procedure. ${ }^{5}$

Benzyl $2 H$-azirine-3-carboxylate 3a was not isolated but instead freshly prepared $2 \mathrm{H}$-azirine in toluene was used directly to react with diazomethane (Scheme 1). ${ }^{6}$ The azirine solution was cooled at $0^{\circ} \mathrm{C}$ and diazomethane was added in excess. The reaction mixture was then left at room temperature for $12 \mathrm{~h}$. One product (6a) was obtained in $49 \%$ yield. The process involves the reaction of $2 \mathrm{H}$-azirine 3a with diazomethane, leading to the cycloadduct $4 \mathbf{a}$ which undergoes a rearrangement generating the allyl azide 5a. This compound participates in a second 1,3-dipolar cycloaddition with diazomethane to give benzyl 3-azidomethyl4,5-dihydro-3 $H$-pyrazole-3-carboxylate $\mathbf{6 a}$.

Encouraged by this result we went on to study the reactivity of methyl $2 \mathrm{H}$-azirine-3-carboxylate $\mathbf{3 b}$ towards diazomethane. Methyl 2-azidoacrylate $\mathbf{2 b}$ was prepared from the reaction of methyl 2,3-dibromopropionate with sodium azide using the procedure described for the ethyl ester. ${ }^{7}$ The thermolysis of methyl 2-azidoacrylate $\mathbf{2} \mathbf{b}$, was carried out as described above for acrylate 2a although it was found that the conversion into methyl $2 \mathrm{H}$-azirine-3-carboxylate $\mathbf{2 b}$ was complete after 2 hours. A solution of the $2 \mathrm{H}$-azirine in toluene was treated with diazomethane, allowing the synthesis of methyl 3-azidomethyl-4,5-dihydro-3 $H$-pyrazole-3-carboxylate $\mathbf{6 b}$ in $38 \%$ yield (Scheme 1).

Gilchrist et al. reported the generation of methyl $2 \mathrm{H}$ azirine-3-carboxylate $\mathbf{2 b}$ although the reactivity of this heterocycle, described as highly unstable and volatile, was not studied. ${ }^{8}$ The reaction of tert-butyl $2 \mathrm{H}$-azirine3-carboxylate, generated in situ from the corresponding $\alpha$-azidoacrylate, with an azomethine ylide giving functionalized $\beta$-lactams has also been reported. ${ }^{\text {le }}$ The same authors indicate that a similar reaction can be promoted with methyl $2 \mathrm{H}$-azirine-3-carboxylate $\mathbf{2} \mathbf{b}$.
The synthesis of 4,5-dihydro-3H-pyrazole-3-carboxylates (6a and $\mathbf{6 b}$ ) constitutes a new example of 1,3-dipolar cycloaddition of $\mathrm{C}-2$ unsubstituted $2 \mathrm{H}$-azirine3-carboxylates.

Aziridines undergo thermal ring opening in a conrotatory manner to generate azomethine ylides which participate in cycloadditions with $2 H$-azirines giving bicyclic heterocycles. ${ }^{1 \mathrm{a}, \mathrm{d}} \mathrm{We}$ decided to explore similar reactions using methyl 2-bromo-3-phenyl- $2 H$-azirine-2carboxylate $\mathbf{1}$ as dipolarophile.

Ethyl (3S,2R)-3-phenylaziridine-2-carboxylate 7 was prepared as described in the literature. ${ }^{9}$ After heating a solution of this aziridine and $2 H$-azirine 1 in toluene for two hours the pyrimidine $\mathbf{1 1}$ was isolated in $12 \%$ yield. Thus, we could conclude that 2-bromo- $2 \mathrm{H}$ azirine 1 participated in the 1,3-dipolar cycloaddition with the azomethine ylide generated from 7 by thermal ring opening. The cycloadduct 9 underwent a ring opening reaction with elimination of $\mathrm{HBr}$, leading to dihydropyrimidine $\mathbf{1 0}$ followed by the aromatisation to 2,5-diphenylpyrimidine-4,6-dicarboxylate $\mathbf{1 1}^{10}$ (Scheme 2).

In conclusion, we have proved that $\mathrm{C}-2$ unsubstituted $2 \mathrm{H}$-azirine-3-carboxylates participate in 1,3-dipolar cycloadditions with diazomethane, leading to new 4,5dihydro-3 $H$-pyrazole derivatives. Methyl 2-bromo-3phenyl- $2 H$-azirine-2-carboxylate can also act as a dipolarophile and its reaction with an azomethine ylide gave 2,5-diphenylpyrimidine-4,6-dicarboxylate. This study has shown that $2 \mathrm{H}$-azirines are an attractive system to be explored for the synthesis of new compounds via 1,3-dipolar cycloaddition.

\section{Acknowledgements}

The authors wish to thank Dr. R. Storr (University of Liverpool, U.K.) for very useful discussions concerning this project. They also thank Chymiotechnon and Fundação para a Ciência e a Tecnologia (POCTI/36137/ QUI/2000) for financial support.

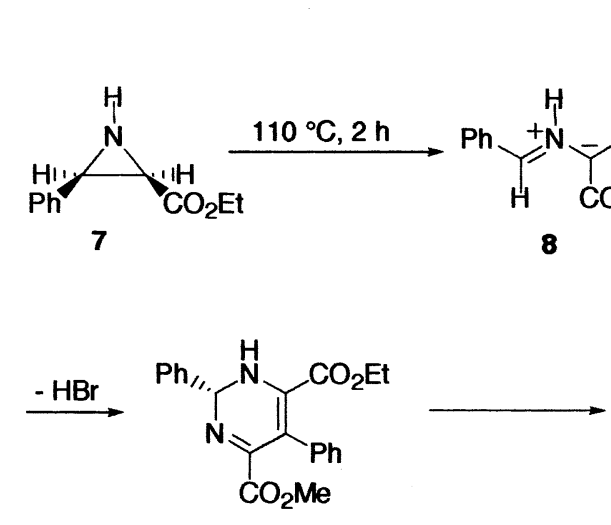

10<smiles>CCOC(=O)c1nc(-c2ccccc2)nc([N+]([O-])O[Na])c1-c1ccccc1</smiles>

$11,12 \%$

Scheme 2. 


\section{References}

1. (a) Anderson, D. J.; Hassner, A. Synthesis 1975, 483-495; (b) Padwa, A.; Woolhouse, A. D. In Comprehensive Heterocyclic Chemistry; Katritzky, A. R.; Rees, C. W., Eds.; Pergamon Press: Oxford, 1984; Vol. 7, pp. 47-93; (c) Nair, V. In Heterocyclic Compounds; Hassner, A., Ed.; John Wiley and Sons: New York, 1983; Vol. 42, pp. 215-332; (d) Palacios, F.; Retana, A. M. O.; Marigorta, E. M.; Santos, J. M. Eur. J. Org. Chem. 2001, 2401-2414; (e) Brown, D.; Brown, G. A.; Andrews, M.; Large, J. M.; Urban, D.; Butts, C. P.; Hales, N. J.; Gallagher, T. J. Chem. Soc., Perkin Trans. I 2002, 2014-2021.

2. Logothesis, A. L. J. Org. Chem. 1964, 29, 3049-3052.

3. (a) Pinho e Melo, T. M. V. D.; Lopes, C. S. J.; Cardoso, A. L.; Rocha Gonsalves, A. M.d'A. Tetrahedron 2001, 57, 6203-6208; (b) Pinho e Melo, T. M. V. D.; Lopes, C. S. J.; Rocha Gonsalves, A. M.d'A.; Beja, A. M.; Paixão, J. A.; Silva, M. R.; Alte da Veiga, L. J. Org. Chem. 2002, 67, 66-71; (c) Pinho e Melo, T. M. V. D.; Lopes, C. S. J.; Rocha Gonsalves, A. M. d'A.; Storr, R. C. Synthesis 2002, 605-608.

4. Gallagher, T. C.; Storr, R. C. Tetrahedron Lett. 1981, 22, 2909-2912.

5. Gilchrist, T. L.; Mendonça, R. Synlett 2000, 1843-1845.

6. Benzyl 3-azidomethyl-4,5-dihydro-3H-pyrazole-3-carboxylate $\mathbf{6 a}$. A solution of benzyl 2-azidoacrylate $\mathbf{2 a}^{5}$ $(0.34 \mathrm{~g}, 1.7 \mathrm{mmol})$ in dry toluene $(40 \mathrm{~mL})$ was heated at reflux for $5 \mathrm{~h}$. The reaction was followed by TLC and IR by monitoring the disappearance of the band corresponding to the azido group $\left(v=2113 \mathrm{~cm}^{-1}\right)$ of the starting azidoalkene. The solution was cooled to $0^{\circ} \mathrm{C}$ and freshly prepared diazomethane solution was added in excess. The reaction mixture was left at room temperature for $12 \mathrm{~h}$ and the solvent was evaporated off. The crude product was purified by flash chromatography [hexane-ethyl acetate $(2: 1)$ ] giving compound $\mathbf{6 a}$ as an oil $(49 \%) . v_{\max }$ (film) $2108,1737 \mathrm{~cm}^{-1} ; \delta_{H}\left(\mathrm{CDCl}_{3}, 300 \mathrm{MHz}\right) 1.70(1 \mathrm{H}, \mathrm{ddd}, J$ 13.0, 9.4 and $6.7 \mathrm{~Hz}), 2.03(1 \mathrm{H}$, ddd, $J 13.0,9.4$ and 5.7 $\mathrm{Hz}), 3.91(1 \mathrm{H}, \mathrm{d}, J 12.9 \mathrm{~Hz}), 4.11(1 \mathrm{H}, \mathrm{d}, J 12.9 \mathrm{~Hz}), 4.66$ $(1 \mathrm{H}$, ddd, $J 18.2,9.4$ and $6.7 \mathrm{~Hz}), 4.78(1 \mathrm{H}$, ddd, $J 18.2$, 9.4 and $5.7 \mathrm{~Hz}), 7.30-7.39(5 \mathrm{H}, \mathrm{m}, \mathrm{Ar}-\mathrm{H}) ; \delta_{C}\left(\mathrm{CDCl}_{3}\right.$, 75.5 MHz) 23.4, 53.9, 68.2, 79.6, 98.3, 128.9, 129.1, 135.3 and $168.4 ; m / z(\mathrm{CI}) 277\left[\mathrm{M}+\mathrm{NH}_{4}\right]^{+}(58 \%)$ and $260\left[\mathrm{MH}^{+}\right]$ (86).

7. Ghosh, S. K.; Verma, R.; Ghosh, U.; Mamdapur, V. R. Bull. Chem. Soc. Jpn 1996, 69, 1705-1711.

8. Alves, M. J.; Gilchrist, T. L. Tetrahedron Lett. 1998, 39, 7579-7582.

9. Gelas-Mialhe, Y.; Touraud, E.; Vessiere, R. Can. J. Chem. 1982, 60, 2830-2851.

10. 2,5-Diphenylpyrimidine-4,6-dicarboxylic acid 4-ethyl ester 6-methyl ester 11. A solution of ethyl $(3 S, 2 R)-3$-phenylaziridine-2-carboxylate $\mathbf{1 1}^{9}(0.1 \mathrm{~g}, 0.55 \mathrm{mmol})$ and methyl 2-bromo-3-phenyl-2 $H$-azirine-2-carboxylate $\mathbf{1}^{\text {3a }}(0.14 \mathrm{~g}$, $0.55 \mathrm{mmol})$ in dry toluene $(15 \mathrm{~mL})$ was heated at reflux for 2 hours. The solvent was evaporated off and the crude product was purified by flash chromatography [hexane-ethyl acetate (3:1), hexane-ethyl acetate (2:1), hexane-ethyl acetate (1:1)] giving compound $\mathbf{1 1}$ as an oil $(12 \%) . \delta_{H}\left(\mathrm{CDCl}_{3}, 300 \mathrm{MHz}\right) 1.16(3 \mathrm{H}, \mathrm{t}, J 7 \mathrm{~Hz}), 3.85$ (3H, s), $4.31(2 \mathrm{H}, \mathrm{q}, J 7 \mathrm{~Hz}), 7.47-7.49(6 \mathrm{H}, \mathrm{m}, \mathrm{Ar}-\mathrm{H})$ and 7.71-7.74 $(4 \mathrm{H}, \mathrm{m}, \mathrm{Ar}-\mathrm{H}) ; \delta_{C}\left(\mathrm{CDCl}_{3}, 75.5 \mathrm{MHz}\right)$ $13.7,53.1,62.4,128.6,128.7,128.7,129.9,130.0,135.9$. $144.2,144.9,149.7,149.8,166.0$ and $166.4 ; m / z 362\left(\mathrm{M}^{+}\right.$, 70\%), 290 (100), 273 (24), 231 (42), 129 (23), 105 (35) and 77 (27). 